\title{
EL DESARROLLO DE LA EDUCACIÓN A DISTANCIA EN LA UNIVERSIDAD NACIONAL DEL LITORAL. DEBILIDADES Y FORTALEZAS
}

\author{
Tesista \\ Walter C. Sotil \\ Director de tesis \\ Horacio Andrés Capanegra
}

La educación superior a distancia en las universidades de Argentina mediante la utilización de campus virtuales es un proceso que inició entre los años 1999 y 2000, impulsado por la evolución tecnológica, y en estos últimos años ha tenido un avance considerable. Este sistema plantea un nuevo modelo en la educación superior, ya que rompe con el esquema tradicional de la educación que se venía desarrollando. En particular, la educación pública a distancia permite al Estado tener presencia, es decir, expresado de otra manera, el Estado se "traslada" a distintos lugares para educar. En este sentido, la Universidad Nacional del Litoral (UNL) se alza como una de las pioneras en el país en implementar la modalidad de educación a distancia.

Transcurridos ya más de quince años desde sus inicios, UNLVirtual se ha consolidado como una propuesta universitaria de educación a distancia a nivel nacional, contando actualmente con una población estudiantil de más de siete mil alumnos en todo el territorio argentino, permitiendo a la UNL otorgarle experiencia en la implementación de nuevas tecnologías para la enseñanza a distancia y una oferta diversa que incluye cursos de formación, carreras de pregrado, grado y recientemente de posgrado. Si bien, por un lado existen muchos datos alentadores en cuanto a la modalidad, por otro lado hay señales, de información proveniente de distintos informes y observaciones realizadas, que indican que $\underline{183}$ existen algunos aspectos a explorar.

En este trabajo se presenta el estudio de la modalidad de educación a distancia en el ámbito de la UNL. Se analiza desde los inicios del Programa de Educación a Distancia hasta el año 2015, sosteniendo que el mismo tiene fortalezas y debilidades. También posee la intención de contribuir a repensar la política educativa universitaria como política de Estado. En la propuesta se trabajó en torno a exponer el problema para tratar de encontrar posibles soluciones.

Los procesos de incorporación de TIC que dan lugar a la construcción de campus virtuales no se pueden explicar teniendo en cuenta un solo factor, es por ello que desde esta propuesta se realizó el análisis en torno al estudio de cuatro dimensiones: Institucional, Tecnológica, de Gestión y de Enseñanza. Aunque esas dimensiones constituyen solo una parte de todas las posibilidades existentes, consi- 
deramos que su análisis es muy importante para intentar comprender los alcances de esta tesis. Se definieron un conjunto de variables en cada dimensión, con fines de diagnóstico, que permitieron identificar diferentes factores críticos en la educación a distancia en la UNL. Algunas de los aspectos examinados fueron la cobertura territorial educativa, la tasa de crecimiento de la población estudiantil, las innovaciones tecnológicas incorporadas en el campus virtual, el análisis de algunos aspectos relacionados a la seguridad informática, el acceso a becas, pasantías y espacios de bolsas de trabajo de alumnos y graduados de la modalidad y el análisis de las aulas virtuales desde la perspectiva de la enseñanza.

En cuanto a las consideraciones metodológicas utilizadas, este trabajo es una investigación de tipo evaluativo, que busca medir los efectos del Programa de Educación a Distancia de la UNL y que permitan tomar decisiones con menor incertidumbre. El modelo de investigación planteado es cualitativo y cuantitativo, tomando como ámbito de investigación a las Unidades Académicas de la Universidad Nacional del Litoral, al Centro Multimedial de Educación a Distancia, a la Dirección de Informatización y Programación Tecnológica, al Centro de Telemática y al campus virtual de la UNL denominado UNLVirtual. Para abordar la metodología propuesta, se recurrió a la revisión de fuentes documentales (principalmente a documentos oficiales de la UNL), a entrevistas semi-estructuradas a informantes claves y a la observación. En particular para la dimensión de enseñanza, se basó principalmente en la recolección de información cuantitativa pro- veniente de encuestas que fueron efectuadas en distintas Unidades Académicas de la UNL.

Dada la información suministrada en este trabajo de investigación se verificó la existencia de condicionantes provenientes de distintas dimensiones, aunque también es necesario destacar que en el análisis se encontraron aspectos muy positivos, que indican que esta modalidad es muy adecuada a la realidad actual de empleo masivo de nuevas TICs. El trabajo realizado reflejó que, si bien el crecimiento de la educación a distancia en la UNL ha sido vertiginoso en los últimos años aún se encuentra en camino hacia su madurez, existiendo aspectos altamente valorables, como así también otros a desarrollar. De este modo, evidenciar las fortalezas y debilidades de la educación a distancia en la UNL, ayuda a plantear una mirada reflexiva acerca del futuro de esta modalidad y su rol en la sociedad.

Por último, realizando un análisis con una mirada más amplia, el trabajo deja planteada una agenda, donde se pueden remarcar algunas zonas de interés que podrían abordarse en el marco de otra instancia posterior, anhelando el fortalecimiento de la modalidad de educación a distancia en la UNL. Entre los puntos más destacados, se encuentran: la necesidad de tener un mayor apoyo político y de liderazgo para profundizar esta modalidad de gestión, correlacionar la oferta con la demanda educativa, innovar en distintas estrategias didácticas para colaborar en la tarea del proceso de enseñanza aprendizaje, equiparar la ciudadanía universitaria con los alumnos de modalidad presencial y la necesidad de avanzar en el campo de investigación empleando estas plataformas.

\section{PARA CITAR ESTE ARTÍCULO:}

Sotil, W.C. (2018). "Recensión de tesis: "El desarrollo de la Educación a Distancia en la Universidad Nacional del Litoral. Debilidades y fortalezas"”, DAAPGE, año 18, No 31 (jul-dic), 2018, pp. 183-184. Santa Fe, Argentina: UNL. 